\title{
Desempenho produtivo de genótipos de morangueiro de dia neutro na Serra Gaúcha
} \author{
Aike Anneliese Kretzschmar ${ }^{2}$ \\ ' Universidade de Caxias do Sul - UCS \\ E-mail:ccocco@ucs.br; gwschildt@ucs.br; fergiacomel737@hotmail.com \\ ${ }^{2}$ Centro de Ciências Agroveterinárias, Universidade do Estado de Santa Catarina - UDESC \\ E-mail: antonio.fagherazzi@gmail.com; dsuekzanin@gmail.com; aike.kretzschmar@udesc.br
}

Carine Cocco', Gabriela Weber Schildt', Fernando Giacomel', Antônio Felippe Fagherazzi², Daniel Suek Zanin²,

Submetido em: 28 set. 2019. Aceito: 04 mar. 2020. DOI: http://dx.doi.org/10.21674/2448-0479.62.155-163

\section{Resumo}

O cultivo de morango durante os meses de verão, considerado período de entressafra, desperta interesse na região da Serra Gaúcha. Para isso, cultivares de dia neutro têm sido utilizadas, já que estas não sofrem interferência da elevação do fotoperíodo para a indução floral. Assim, o presente estudo teve como objetivo avaliar a produção de diferentes genótipos de morangueiro de dia neutro na Região da Serra Gaúcha. Foram avaliadas as cultivares Albion, San Andreas e Irma, e as seleções FRF FC 104.01, FRF FC 57.06 e FRF FC 191.02, implantadas no município de Farroupilha - RS, em maio de 2017. Utilizou-se delineamento inteiramente casualizado contendo quatro repetições, e unidade experimental composta por 10 plantas. Foram avaliadas variáveis produtivas e de qualidade físico-química das frutas. Obteve-se nas cultivares americanas Albion e San Andreas, e na seleção italiana FRF FC I04.0I maior produção de frutas, estabilidade no tamanho das frutas e prolongamento do ciclo produtivo. Os genótipos italianos destacam-se na relação sólidos solúveis/acidez titulável. Nas condições do estudo, observou-se que a cultivar italiana Irma não expressa seu potencial produtivo.

Palavras-chave: Fragaria x ananassa. Produção. Qualidade. Adaptabilidade.

\section{Abstract}

\section{Yield performance of Italian neutral-day strawberry cultivars and genotypes in Serra Gaúcha}

The strawberry cultivation during the summer months, considered the off-season, arouses interest in the Serra Gaúcha region. For this, neutral day cultivars have been used, as they do not suffer interference from the increase of the photoperiod for floral induction. Thus, the present study aimed to evaluate the yield of different cultivars and genotypes of neutral day strawberry. The cultivars Albion, San Andreas and Irma, and the selected genotypes FRF FC 104.0I, FRF FC 57.06 e FRF FC 191.02 were evaluated and implanted in the municipality of Farroupilha - RS in May 2017, in a completely randomized design with 4 repetitions, each plot consisting of 10 plants. The yield, the average fruit mass and the physical-chemical quality of the fruits were evaluated. The American cultivars Albion and San Andreas, as well as the Italian genotype FRF FC 104.0I presented higher fruit yield, stability in strawberry size and prolongation of the productive cycle. The italian genotypes stood out at the soluble solids and titratable acidity characters. Under the conditions of the study, it was observed that the Italian cultivar Irma does not express its productive potential.

Keywords: Fragaria x ananassa. Yield. Quality. Adaptability. 


\section{Introdução}

O morangueiro é produzido e apreciado nas diversas regiões do mundo, caracterizando-se pela alta rentabilidade por área e intensa demanda por mão de obra. No Brasil, a produção é realizada em vários estados, especialmente Minas Gerais, Paraná e Rio Grande do Sul (FAGHERAZZI et al, 2016). No Rio Grande do Sul, a produção de morangos concentra-se nas regiões de Pelotas, Vale do Caí e Serra Gaúcha. Dados da Emater, estimam que no estado, o cultivo do morangueiro é realizado em cerca de 500 hectares, nos quais são produzidos anualmente cerca de 23 mil toneladas da fruta, com média de 46 toneladas por hectare, envolvendo cerca de 2.000 propriedades rurais na produção. Na Serra Gaúcha, onde se concentram os maiores produtores, a produção anual de morangos gira em torno de 15,4 mil toneladas (RIO GRANDE DO SUL, 2019).

A popularização do morangueiro no estado gaúcho tem sido impulsionada por novas técnicas de cultivo. Dentre elas, destaca-se a vertiginosa migração do sistema tradicional de cultivo no solo, para o cultivo em substratos, hoje presente em $80 \%$ das áreas de produção (COSTA et al, 2019; GONÇALVES et al, 2016). Conforme Andriolo et al, (2009), a maior facilidade para realizar o manejo das plantas, em razão da maior ergonomia, bem como a redução do uso de agroquímicos para controle de pragas e doenças, tem proporcionado aumento na produção e qualidade da fruta. Estes princípios têm proporcionado aumento na rentabilidade da cultura e, este tem sido o principal fator para a adoção da cultura em propriedades familiares, como opção para a diversificação da renda (OLIVEIRA; BELARMINO; BELARMINO, 20I7). Ademais, tem atraído de volta para o meio rural jovens que haviam ido em busca de melhores oportunidades de trabalho em grandes centros urbanos (RIO GRANDE DO SUL, 2019).

A produção de morangos até recentemente era baseada no uso de cultivares de dia curto, principalmente no Rio Grande do Sul. Nese grupo de cultivares, a diferenciação floral é favorecida por fotoperíodos menores de 14 horas e temperaturas noturnas entre 8 e $15^{\circ} \mathrm{C}$ (ANTUNES; REISSER; SCHWENGBER, 20I6). Essas cultivares, em condições de temperaturas elevadas e de dias longos, têm maior crescimento vegetativo em detrimento do reprodutivo. Como consequência, a partir de novembro até o início do inverno, se registrava menor oferta da fruta no mercado, e elevação dos preços de mercado.

Em contrapartida, a utilização de cultivares insensíveis ao fotoperíodo ou de dia neutro, oferecem potencial para estender a estação de frutificação do morangueiro, especialmente em regiões com verões amenos, como é o caso da Serra Gaúcha. Nesta região, cultivares de dias neutros florescem continuamente durante os meses de verão. Neste caso, o principal fator limitante à diferenciação floral é a temperatura diurna, já que diferenciam gemas floríferas sempre que a temperatura estiver abaixo de $28^{\circ} \mathrm{C}$ (ANTUNES; REISSER; SCHWENGBER, 2016). Este grupo de cultivares vêm sendo amplamente utilizado, destacando-se Albion e San Andreas como as mais cultivadas.

No país, o número de cultivares com a característica de neutralidade ao fotoperíodo é restrito. Um dos motivos é que os programas de melhoramento genético brasileiros se encontram inativos ou não tem lançado nenhuma nova cultivar (BARNECHE; BONOW, 20I2; ZEIST; RESENDE, 20I9). Devido à falta de interesse das empresas privadas e públicas, criou-se uma dependência de cultivares importadas, o que impacta fortemente nos custos de produção da cultura (SOUZA et al, 2019). Cabe salientar que a maioria destas cultivares são oriundas de países com condições climáticas distintas e, tornam-se mais suscetíveis a doenças em locais com alta umidade relativa do ar e temperatura elevada, propícias à proliferação de fungos e bactérias (GALVÃO et al, 2017). Assim, é importante incentivar os programas nacionais de melhoramento genético e a introdução de cultivares (OLIVEIRA; SCIVITTARO, 20I I), visando ampliar os recursos genéticos disponíveis para implantação de áreas comerciais.

A avaliação de cultivares a serem plantadas em uma região tradicional é uma ferramenta importante para que os produtores possam tomar suas decisões em relação à substituição de materiais antigos por cultivares melhor adaptadas (GUIMARÃES et al, 20I5), bem como para a indicação de novos genótipos por programas de melhoramento genético. Deste modo, a seleção de plantas com melhores características produtivas e qualitativas, proporcionam maior rentabilidade no seu cultivo. Este estudo objetivou avaliar a produção e qualidade das frutas produzidas por genótipos de morangueiro de dia neutro nas condições da Região da Serra Gaúcha. 
O experimento foi conduzido no período de maio de 2017 a janeiro de 2018 , em área de produção comercial, na Linha Julieta, $1^{\circ}$ Distrito do município de Farroupilha, no Estado do Rio Grande do Sul. O clima dessa região se caracteriza como temperado, com verão ameno, inverno frio e chuvas uniformes, segundo classificação de Köppen sendo do tipo $\mathrm{Cfb}$. A média pluviométrica anual é de $1.80 \mathrm{I} \mathrm{mm}$ e a temperatura média de $17,2{ }^{\circ} \mathrm{C}$.

Os tratamentos consistiram em cultivares e seleções de morangueiro de dias neutros, sendo avaliadas as cultivares americanas Albion e San Andreas, a cultivar italiana Irma e as seleções italianas FRF FC 104.0I, FRF FC 57.06 e FRF FC 191.02. Os genótipos e a cultivar de origem italiana foram desenvolvidos na Itália, pelo Consiglio per la Ricerca in Agricoltura e L'Analisi Dell'Economia Agraria - Centro di Ricerca Olivicoltura, Frutticoltura e Agrumicoltura (CREA-OFA-FRF), que em 20I2, por meio da 'Convenção para a experimentação e difusão do material genético de morangueiro italiano no Brasil', foram introduzidos no Brasil pelo Centro de Ciências Agroveterinárias da Universidade do Estado de Santa Catarina (CAV/UDESC). O delineamento experimental foi inteiramente casualizado, com quatro repetições, sendo cada parcela experimental composta por 10 plantas úteis.

Para a implantação foram utilizadas mudas frescas do tipo 'raiz nua', produzidas em sistema de cultivo no solo, por um viveiro nacional com atividade de produção de mudas de morangueiro reconhecida pelo Ministério da Agricultura Pecuária e Abastecimento (MAPA). O sistema para produção das frutas foi em calhas suspensas preenchidas com substrato, na altura de I metro do solo e espaçamento entre plantas de $0,2 \mathrm{~m}$, com duas calhas por bancada de cultivo. O substrato utilizado foi composto por $70 \%$ de casca de arroz carbonizada e $30 \%$ de turfa fértil. Sobre cada calha acondicionou-se cobertura plástica com $100 \mu \mathrm{m}$ de espessura e instalado a $0,75 \mathrm{~cm}$ de altura, formando um sistema de mini túnel suspenso, com arcos de aço galvanizado. O plantio foi realizado em 25 de maio de 2017.

A nutrição das plantas foi realizada de acordo com a recomendação da empresa Yara Fertilizantes, sendo dividida em fase vegetativa e reprodutiva. A irrigação foi realizada uma vez ao dia, sempre no período do dia com temperatura mais elevada. Os manejos fitotécnicos realizados foram duas limpezas para a retirada das folhas mais velhas e doentes, na primeira quinzena de agosto e de novembro. $O$ controle do aumento excessivo da temperatura, bem como a renovação do ar no interior dos túneis, foi realizado mediante a abertura lateral do plástico de revestimento nas primeiras horas da manhã e fechamento ao entardecer. Em dias de chuva e ventos fortes, foram mantidos parcial ou totalmente fechados, dependendo das condições climáticas.

A colheita iniciou em seis de setembro de 2017 e encerrou em vinte e um de janeiro de 2018 , sendo realizada semanalmente. O ponto de colheita foi determinado pela coloração da epiderme, com $100 \%$ da epiderme avermelhada, no estádio de maturação completa. Avaliou-se a produção, obtida através do somatório da massa fresca de frutas, sendo expressa em gramas ( $\mathrm{g}$ ) por planta; número médio de frutas, obtido através do somatório do número em cada planta em cada colheita; massa média, expressa em gramas ( $g$ fruta-1), obtida pelo quociente entre a massa fresca e o número médio de frutas por planta, durante os períodos de avaliação. A produção foi obtida a partir do somatório da massa em cada colheita. Para as avaliações, foram contabilizadas apenas as frutas comerciais, sendo selecionadas com base na massa fresca. Frutas com defeitos graves ou massa fresca inferior a cinco gramas foram consideradas não comerciais e descartadas.

Os parâmetros de qualidade das frutas foram avaliados nos meses de outubro e novembro, considerados os meses do ápice produtivo. A coloração da fruta foi obtida por leituras realizadas na região equatorial, com auxílio de colorímetro Minolta 400/4I0. As medições foram realizadas na escala tridimensional $L^{*} a^{*} b^{*}$ do sistema CIELAB e os resultados expressos em valores da tonalidade da coloração (ângulo HUE) e luminosidade (L*) (ÁVILA et al, 20I2). Para a realização da avaliação dos parâmetros de qualidade, foram selecionados de forma aleatória, dez frutas representativos de cada repetição. A firmeza de polpa, expressa em Newton, foi mensurada através de um penetrômetro digital com ponteira de $7 \mathrm{~mm}$, sendo as leituras realizadas na região equatorial, com duas leituras por fruta, em lados opostos. $O$ teor de sólidos solúveis foi obtido a partir da homogeneização de uma amostra de dez frutas por repetição, sendo mensurado em refratômetro digital, com compensação de temperatura, cujo os valores foram expressos em ${ }^{\circ}$ Brix; a acidez titulável foi obtida através da titulação de uma amostra composta por $5 \mathrm{~mL}$ do suco de morango e os resultados expressos em \% de ácido cítrico. Com os dados de sólidos solúveis (SS) e acidez titulável (AT), calculou-se a relação SS/AT.

Os dados foram submetidos à análise de variância e quando significativo as médias foram comparadas entre si pelo teste de Scott-Knott a 5\% de probabilidade de erro, utilizando o software estatístico SISVAR versão 5.6 (FERREIRA, 20I4). 


\section{Resultados e Discussão}

No mês de agosto, quando as plantas estavam no estágio fenológico de plena floração, registraram-se episódios sucessivos de geada no local do experimento, o que ocasionou danos irreversíveis, à floração, resultando em abortamento de flores. Como consequência disso, houve atraso no início da colheita, bem como redução na produção de frutas. Em regiões mais frias, como o caso da Serra Gaúcha, tem-se observado paralisação no crescimento e produção em virtude das baixas temperaturas e geadas, comuns no inverno. Por este motivo, muitos produtores na região realizam o plantio tardio, em meados de junho e julho, de forma a evitar a exposição das plantas a temperaturas negativas durante seu florescimento.

A produção e número de frutas ao longo das 20 semanas de colheita foram separadas entre os meses de colheita, de setembro a janeiro, somando-se a produção obtida em cada mês. Os genótipos italianos FRF FC 104.0I e FRF FC 057.06 e as cultivares Albion e San Andreas apresentaram maior produção no mês de setembro (Figura IA). San Andreas manteve desempenho superior também no mês de outubro.

Observou-se que no mês de janeiro, somente as cultivares americanas Albion e San Andreas e o genótipo italiano FRF FC 104.01 mantiveram produção. Esta é uma característica importante para genótipos de dia neutro de morangueiro, cultivados na Serra Gaúcha, tendo em vista que temperaturas mais amenas durante os meses de verão, possibilitam estender o período produtivo da cultura. A produção nos meses de verão e outono proporciona melhores preços para o produto (FAGHERAZZI et al, 20I6), o que justifica a busca por técnicas de manejo e cultivares que viabilizem a produção em períodos de escassez de frutas.

A cultivar italiana Irma apresentou menor rendimento nos meses de setembro a novembro, não produzindo morangos nos meses de dezembro e janeiro, o que denota sua falta de adaptação às condições climáticas do sul do Brasil. Cabe salientar que em condições climáticas italianas, Irma apresenta comportamento produtivo de neutralidade ao fotoperíodo (FAEDI et al, 2009). Este resultado comprova a forte interação genótipo e ambiente na cultura do morangueiro, visto que genótipos que não se adaptam ao ambiente de cultivo, como Irma são, portanto, pouco produtivos e vulneráveis a fatores bióticos e abióticos (BARNE$\mathrm{CHE}$; BONOW, 20I2). A paralisação na produção em alguns genótipos pode estar relacionada à elevação da temperatura acima de $28^{\circ} \mathrm{C}$, que restringem a indução floral em genótipos de dia neutro, observando-se decréscimo na produção de frutas (FAEDI; BARUZZI, 2004).

Albion, San Andreas e o genótipo italiano FRF FC I04.0I apresentam comportamento mais estável para a massa média de frutas ao longo do ciclo produtivo. A estabilidade no tamanho de frutas é uma característica essncial na seleção de um novo genótipo para cultivo comercial, pois frutas grandes tornam a operação de colheita e a embalagem mais rápidas, resultando em menor custo de mão-de-obra e assegurando maior lucratividade ao produtor (FAGHERAZZI et al, 20I4). Estes resultados são um fator importante para a escolha da cultivar, pois conforme Wurz et al (20/9), a cultivar pode ser até produtiva, entretanto se as frutas não tiverem potencial de comercialização in natura, pode resultar em baixo valor agregado.

Em relação à produção total de morangos, obtida entre os meses de setembro e janeiro, as cultivares americanas Albion e San Andreas e o genótipo italiano FRF FC 104.01, obtiveram melhor desempenho, com média em torno de 500 gramas por planta (Tabela I). A cultivar Irma apresentou o pior desempenho produtivo, com uma produção cinco vezes menor que a média dos materiais mais produtivos. Esta cultivar também apresentou menor número total e tamanho de morangos. A produção de morangos nos meses de verão, configura uma importante janela de produção para a Serra Gaúcha, tendo em vista que nas demais regiões produtoras do estado, a produção cai drasticamente em decorrência das temperaturas elevadas (FAGHERA$\mathrm{ZZI}$ et al, 20l6). No presente estudo, as colheitas foram realizadas até o final de janeiro, verificando-se que a partir desta data houve uma drástica redução no tamanho de frutas e produção, o que inviabiliza a colheita. 


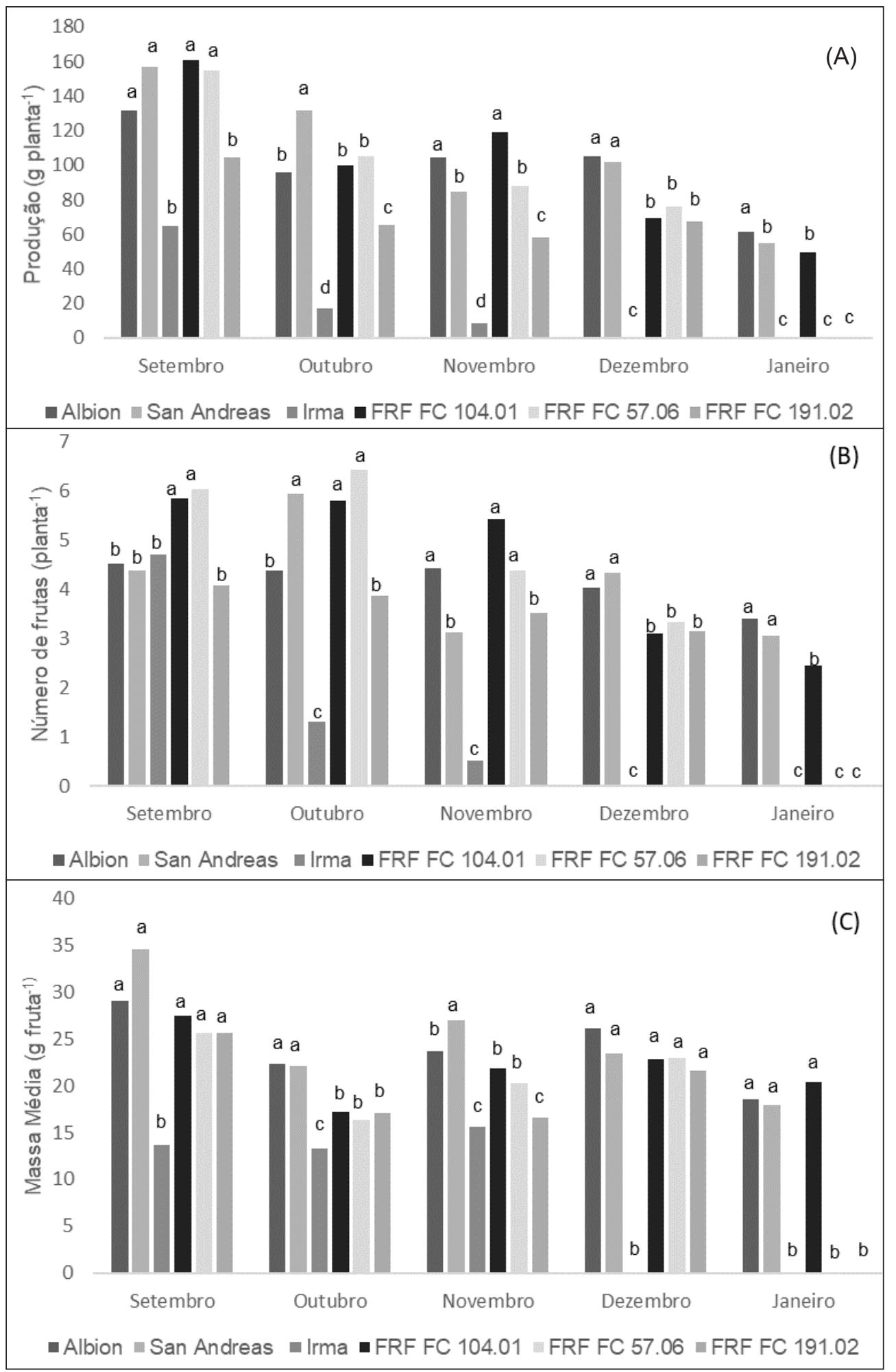

Figura I

Produção (IA), número (IB) e massa média de frutas (IC) de genótipos de morangueiro de dia neutro, ao longo dos meses de produção em Farroupilha - RS. Médias seguidas por letras distintas diferem entre si pelo teste de Scott-Knott, a 5\% de probabilidade de erro.

Tabela I. Produção, número e massa média de genótipos de morangos ao final do ciclo produtivo em Farroupilha - RS.

\begin{tabular}{|c|c|c|c|}
\hline & Produção total & Número de frutas & Massa média \\
\hline Genotipos & $\left(\right.$ g planta $\left.{ }^{-1}\right)$ & & $\left(g\right.$ fruta $\left.{ }^{-1}\right)$ \\
\hline Albion & 498,7 a & 20,7 a & 24,1 a \\
\hline FRF FC 57.6 & $424, I \quad b$ & 20,2 a & $21,0 \mathrm{~b}$ \\
\hline FRF FC 104.01 & 498,5 a & 22,6 a & $22,0 \mathrm{~b}$ \\
\hline FRF FC I91.02 & 296,1 c & 14,6 b & $20,3 \mathrm{~b}$ \\
\hline Irma & $90,3 \mathrm{~d}$ & $6,55 \mathrm{c}$ & $13,8 \mathrm{c}$ \\
\hline San Andreas & $529,3 \mathrm{a}$ & $20,8 \mathrm{a}$ & $25,5 \mathrm{a}$ \\
\hline C.V. (\%) & 10,0 & 8,0 & 9,4 \\
\hline
\end{tabular}

* Médias seguidas de mesma letra, não diferem entre si pelo Teste de Scott-Knott, a 5\% de probabilidade de erro. 
Dentre os parâmetros de coloração de frutas, observou-se variação nos valores $L^{*}$ entre os genótipos e cultivares (Tabela 2 ). $O$ valor $L^{*}$ expressa $\circ$ grau de luminosidade da cor medida $\left(L^{*}=100=\right.$ branco; $L^{*}=$ $0=$ preto); neste caso, do vermelho. Assim, os genótipos que apresentaram maiores valores para esta variável foram FRF FC 57.06 e Irma, indicando que suas frutas tenderam ao vermelho mais claro, enquanto que Albion foi mais propenso a produzir frutas vermelho mais escuro. $\mathrm{Na}$ avaliação de novembro, as cultivares e genótipos apresentaram valores similares para a luminosidade.

A redução dos valores de croma indica redução da saturação de pigmentos da determinada cor; neste caso, da cor vermelha, que se apresenta menos viva. San Andreas e FRF FC 57.6 obtiveram coloração vermelho mais brilhante em outubro. Nesta avaliação, menores valores para croma ocorreram para Albion e FRF FC I04.0I, indicando que estas cultivares produzem frutas mais opacas que as demais. Os valores de croma semelhantes em novembro mostraram que não apresentam escurecimento acentuado das frutas, enquanto os valores de intensidade da cor ( ${ }^{\circ} \mathrm{Hue}$ ) indicaram que a cor vermelha das frutas se manteve similar entre os genótipos.

No mês de outubro, a cor da epiderme dos morangos da cultivar Albion e FRF FC I04.0I, apresentaram pigmentação vermelho-intensa, indicada pelo baixo valor de ângulo Hue ( $\left.{ }^{\circ} \mathrm{h}\right)$. Segundo Ávila et al (20/2), menores valores relativos de ${ }^{\circ}$ Hue indicam coloração mais escura. Desta forma, no presente estudo, observou-se que Irma, FRF FC 57.6 e FRF FC 191.02 apresentam maior luminosidade, denotando sua epiderme relativamente mais clara. $\mathrm{Na}$ avaliação de novembro não houveram diferenças entre os genótipos e cultivares para o valor do ângulo Hue.

A diferença de cor entre cultivares é uma característica genética, influenciada por fatores climáticos e culturais (CANTILLANO; SILVA, 20I0). A coloração do morango se deve à presença de antocianinas, que são pigmentos naturais derivados de açúcares, sendo a principal antocianina a pelargonidina 3-glicosídeo (COCCO et al, 20l5). Assim, com o avanço da maturação ocorre a degradação da clorofila e a síntese de pigmentos antociânicos, o que indica o ponto de maturação para consumo da fruta. Os autores destacam também que a síntese de antocianinas nas frutas e o seu teor são influenciados pelo genótipo, características do clima no local de produção e pelo manejo da planta.

Tabela 2. Coloração da epiderme de morangos de diferentes genótipos nos meses de outubro e novembro em Farroupilha - RS.

\begin{tabular}{lcccccc}
\hline \multirow{2}{*}{ Genótipos } & \multicolumn{5}{c}{ Outubro } & \multicolumn{3}{c}{ Novembro } & & C & Croma & hue \\
\hline Albion & $30,7 \mathrm{~d}$ & $44,5 \mathrm{~d}$ & $30,4 \mathrm{c}$ & 38,4 n.s. & $47, \mathrm{I}^{\text {n.s. }}$ & $35,4^{\text {n.s. }}$ \\
FRF FC 57.06 & $38, \mathrm{I} \mathrm{a}$ & $53,6 \mathrm{a}$ & $35,0 \mathrm{a}$ & 39,9 & 48,0 & 33,3 \\
FRF FC 104.0I & $32,4 \mathrm{c}$ & $45,9 \mathrm{~d}$ & $30,6 \mathrm{c}$ & 38,6 & 47,8 & 35,9 \\
FRF FC 19I.02 & $35,0 \mathrm{~b}$ & $50,0 \mathrm{~b}$ & $34,9 \mathrm{a}$ & 38,0 & 45,8 & 34,6 \\
Irma & $37,4 \mathrm{a}$ & $48,7 \mathrm{c}$ & $36,5 \mathrm{a}$ & 37,4 & 46,9 & 34,9 \\
San Andreas & $33,0 \mathrm{c}$ & $53,4 \mathrm{a}$ & $\mathbf{3 2 , 9} \mathrm{b}$ & $\mathbf{3 7 , 9}$ & 46,4 & 35,0 \\
\hline C.V. (\%) & $\mathbf{3 , 0}$ & $\mathbf{3 , 6}$ & $\mathbf{3 , 8}$ & $\mathbf{2 , 9}$ & $\mathbf{2 , 9}$ & $\mathbf{3 , 0}$ \\
\hline
\end{tabular}

* Médias seguidas de mesma letra, não diferem entre si pelo Teste de Scott-Knott, a 5\% de probabilidade de erro.

A firmeza de polpa apresentou médias superiores a 5,50 N em outubro para San Andreas e genótipos italianos FRF FC 57.06 e FRF FC 104.01. Em novembro, além destes Albion e FRF FC 191.02 obtiveram médias superiores a 4,9 N. Irma obteve menores valores de firmeza de polpa nas avaliações de outubro e novembro (Tabela 3). Esse resultado demonstra sua menor resistência ao armazenamento e transporte após sua colheita. Brackmann et al (20l I) ressaltam que a firmeza da polpa é um dos parâmetros qualitativos mais importantes para o morangueiro, pois está relacionada com a capacidade de conservação dos frutos em pós-colheita.

Albion, San Andreas e o genótipo FRF FC 104.0I apresentaram maiores valores para o teor de sólidos solúveis na avaliação realizada em outubro, enquanto que no mês de novembro não houve diferença, com média dos genótipos de $7,0^{\circ}$ Brix. O teor de sólidos solúveis é um caráter determinado geneticamente (COCCO et al, 20I5; PINELLI et al, 20II) e influenciado pelas condições climáticas, o que explica as diferenças encontradas entre as cultivares estudadas. Em morangos, é esperada variação nos teores de sólidos solúveis de 4,0 a I I,0Brix (CHITARRA; CHITARRA, 2005). Os valores obtidos no presente estudo estão dentro desta faixa. 
San Andreas apresentou maior acidez titulável no mês de outubro, enquanto que em novembro, além de San Andreas, as cultivares Albion e Irma também apresentaram médias superiores. A acidez titulável é um importante atributo químico para os genótipos destinados ao consumo in natura, visto que o consumidor prefere frutas com acidez máxima de 0,8\% (CHITARRA; CHITARRA, 2005). Alguns estudos têm demonstrado que a acidez titulável pode variar nas frutas ao longo do ciclo produtivo, em função de que o aumento da exposição à luz em dias ensolarados, promove aumento da temperatura das frutas de até 8 ${ }^{\circ} \mathrm{C}$ em relação a temperatura do ar no ambiente, o que promove aumento nos níveis de acidez (TAGHAVI; SIDDIQUI; RUTTO, 2019).

A relação sólidos solúveis/acidez titulável (SS/AT), permite a avaliação do sabor dos frutas, sendo mais representativa do que a medição isolada do teor de açúcares e de acidez titulável e é usada como indicador de palatabilidade de frutas (CHITARRA; CHITARRA, 2005). No mês de outubro, essa relação foi superior em Albion, FRF FC 57.06, FRF FC 104.01, FRF FC 191.02, apresentando valores em torno de 12,0. A avaliação realizada em novembro, a relação SS/AT revelou valores superiores a outubro, com destaque para os genótipos italianos FRF FC 104.01, FRF FC 191.02 e FRF FC 57.06, que apresentaram médias variando entre 18,6 e 21,5 .

Tabela 3 - Firmeza de polpa, sólidos solúveis (SS), acidez titulável (AT) e relação SS/AT em diferentes genótipos de morangueiro, nos meses de outubro e novembro, em Farroupilha-RS.

\begin{tabular}{|c|c|c|c|c|}
\hline \multirow[t]{2}{*}{ Genótipos } & Firmeza de polpa & Sólidos Solúveis & Acidez titulável & SS/AT \\
\hline & (Newton) & ( ${ }^{\circ}$ Brix $)$ & (\% ácido cítrico) & \\
\hline & \multicolumn{4}{|c|}{ Outubro } \\
\hline Albion & $5,2 b$ & $6,7 \mathrm{a}$ & $0,5 \mathrm{~b}$ & $12,3 \mathrm{a}$ \\
\hline FRF FC 57.06 & $5,8 \mathrm{a}$ & $5,6 b$ & $0,5 \mathrm{c}$ & $11,7 \mathrm{a}$ \\
\hline FRF FC I04.0I & $5,5 \mathrm{a}$ & 6,1 a & $0,5 \mathrm{c}$ & 13,1 a \\
\hline FRF FC 191.02 & $4,5 \mathrm{c}$ & $5,7 b$ & $0,5 \mathrm{c}$ & $12,5 \mathrm{a}$ \\
\hline Irma & $3,4 \mathrm{~d}$ & $5,0 \mathrm{~b}$ & $0,5 \mathrm{c}$ & $10,9 \mathrm{~b}$ \\
\hline San Andreas & $5,6 \mathrm{a}$ & $6,2 \mathrm{a}$ & $0,6 \mathrm{a}$ & $9,8 \mathrm{~b}$ \\
\hline \multirow[t]{2}{*}{ C.V. (\%) } & 2,9 & 10,0 & 6,3 & 9,6 \\
\hline & \multicolumn{4}{|c|}{ Novembro } \\
\hline Albion & $4,9 \mathrm{a}$ & $7, I^{\text {n.s. }}$ & $0,4 \mathrm{a}$ & $16,3 \mathrm{~b}$ \\
\hline FRF FC 57.06 & $5,5 \mathrm{a}$ & 7,4 & $0,3 \mathrm{~b}$ & $21,5 \mathrm{a}$ \\
\hline FRF FC I04.01 & $5,0 \mathrm{a}$ & 6,8 & $0,4 \mathrm{~b}$ & $19,0 \mathrm{a}$ \\
\hline FRF FC 191.02 & $5,3 \mathrm{a}$ & 7,1 & $0,4 b$ & $18,6 \mathrm{a}$ \\
\hline Irma & $3,8 \mathrm{~b}$ & 6,5 & $0,5 \mathrm{a}$ & $14,6 \mathrm{~b}$ \\
\hline San Andreas & $5,0 \mathrm{a}$ & 6,8 & $0,4 \mathrm{a}$ & $15,7 \mathrm{~b}$ \\
\hline CV (\%) & 7,6 & 5,7 & 11,5 & 12,9 \\
\hline
\end{tabular}

* Médias seguidas de mesma letra, não diferem entre si pelo Teste de Scott-Knott, ao nível de 5\% de probabilidade. N.s. = não significativo a $5 \%$ de probabilidade.

Segundo Cantillano e Silva (2010), a relação SS/AT pode variar entre 6 e 20, sendo preferido pelos consumidores 0 intervalo de 15 a 18 . Já a indústria normalmente inicia $\circ$ processamento com valor entre I 2 e I3. Brackmann et al (20II) salientam que uma alta relação de sólidos solúveis/acidez titulável favorece um melhor equilíbrio entre o doce e o ácido, conferindo sabor mais agradável às frutas, tornando-as mais atrativas. É possível observar que na medição de novembro, os genótipos italianos apresentaram valores superiores ao intervalo ideal para esta variável, o que reforça seu potencial de produção para consumo in natura. Cabe salientar ainda que na cultivar San Andreas, o elevado teor de sólidos solúveis registrado em outubro, não resultou em incremento na relação SS/AT em virtude de sua elevada acidez titulável.

A colheita em plena maturação alcança frutos no ápice de sua qualidade, mas a qualidade potencial máxima do fruto é ditada por fatores pré-colheita incluindo condições ambientais. Especificamente, temperatura do ar e intensidade da luz durante o desenvolvimento do fruto, demonstraram afetar o teor de sólidos solúveis, acidez titulável e relação SS/AT em morangos (TAGHAVI; SIDDIQUI; RUTTO, 2019), o que pode explicar as diferenças nestes parâmetros nas duas avaliações realizadas. 
É importante destacar que os genótipos italianos que foram utilizados neste estudo, foram obtidos e selecionados no CREA-FRF (Itália). Uma vez no Brasil, têm sido avaliados quando à sua adaptação em diferentes regiões de produção. Por fim, a avaliação de características do genótipos provenientes de programas de melhoramento estrangeiros pode auxiliar na atenuação da baixa disponibilidade de cultivares registradas, especialmente de dias neutros.

\section{Considerações Finais}

O genótipo italiano FRF FC I04.0I apresentou desempenho produtivo similar à Albion e San Andreas em produção, estabilidade no tamanho de morangos e prolongamento do ciclo produtivo.

Os genótipos italianos avaliados apresentam firmeza de polpa similar à Albion e San Andreas e são superiores na relação sólidos solúveis/acidez titulável.

Os genótipos de dia neutro FRF FC 104.0I, Albion e San Andreas são indicados para o cultivo na Região da Serra Gaúcha.

\section{Agradecimentos}

Os autores agradecem à Granja Pasa, pela concessão do espaço e disponibilização dos insumos para a realização do experimento.

\section{Referências}

ANDRIOLO, J. L. et al. Cultivo sem solo do morangueiro com três métodos de fertirrigação. Ciência Rural, v. 39, n. 3, p. 69I-695, 2009.

ÁVILA, J. M. M. de et al. Influência do sistema de produção e do armazenamento refrigerado nas características físico-químicas e no desenvolvimento de compostos voláteis em morangos. Ciência Rural, v. 42, n. 12, p. 2265-227I, 2012.

ANTUNES, L. E. C; REISSER, C. J.; SCHWENGBER, José Ernani. Morangueiro $\square$ Brasília, DF: Embrapa, 2016. 589 p.

BRACKMANN, A. et al. Avaliação de genótipos de morangueiro quanto à qualidade e potencial de armazenamento. Revista Ceres, Viçosa, v. 58, n. 5, p. 542-547, 201 I.

BARNECHE, A. C. de O.; BONOW, S. Novos desafios para o melhoramento genético da cultura do morangueiro no Brasil. Informe Agropecuário, v. 33 n. 268, p. 21-26, 2012.

CANTILLANO, R. F. F.; SILVA, M. M. Manuseio pós-colheita de morangos. Pelotas: Embrapa Clima Temperado, 2010. 37p. (Embrapa Clima Temperado. Documentos, 318).

CHITARRA, M.I.F; CHITARRA, A.B. Pós-colheita de frutas e hortaliças: fisiologia e manuseio. 2ed. Lavras: UFLA, 2005. 785p.

COCCO, C. et al. Effects of site and genotype on strawberry fruits quality traits and bioactive compounds. Journal of Berry Research, v.5, n.3, p. 145-155, 2015.

COSTA, S. I. et al. Parâmetros qualitativos de morangueiros de dias neutros produzidos em cultivo sem solo. Revista Engenharia na Agricultura - REVENG. Paraíba, v. 27, n. 6, p. 48I-489. 2019.

RIO GRANDE DO SUL, Empresa de Assistência Técnica e Extensão Rural. Porto Alegre: 2019 (Gerência de Planejamento). Disponível em: http://www.emater.tche.br/site/arquivos_pdf/conjuntural/conj_24102019.pdf. Acesso em 24 out 2019.

FAEDI, W.; BARUZZI, G. New Strawberry cultivars from italian breeding activity. Acta Horticulturae 649, 8I-84, 2004.

FAEDI, W. et al. ADVANCES IN STRAWBERRY BREEDING FOR NORTH OF ITALY. Acta Horticulturae 842, 545548, 2009.

FAGHERAZZI, A. F. et al. Strawberry production progress in Brazil. In: VIII International Strawberry Symposium, 2016, Quebec. Anais.. Quebec: Horticulture Research Center/INAF, 2016. p. 937-940.

FAGHERAZZI, A. F. et al. La fragolicoltura brasiliana guarda avanti. Frutticoltura, n. 6, p. 20-24, 2014. 
FERREIRA, D.F. Sisvar: a Guide for its Bootstrap procedures in multiple comparisons. Ciência e Agrotecnologia, Lavras, v.38, n.2, p. 109-II2, 2014.

GALVÃO, A. G. et al. Breeding new improved clones for strawberry production in Brazil. Acta Scientiarum. Agronomy, v. 39, n. 2, p. I49-155, 2017.

GONÇALVES, M.A.; et al. Produção de morango fora do solo. Pelotas: Embrapa Clima Temperado (Documentos 4I0), 2016. 32p.

GUIMARÃES, A. G.; et al. Potencial produtivo de cultivares de morangueiro. Revista Brasileira de Fruticultura, Jaboticabal, v. 37, n. I, p. II2-120, mar. 2015.

PINELLI, L.D.O. et al. Antioxidants and other chemical and physical characteristics of two strawberry cultivars at different ripeness stages. Journal of Food Composition and Analysis, v.24, n. I, p.I I-16, 201 I.

OLIVEIRA, R. P.; SCIVITTARO, W. B. Desempenho produtivo de cultivares de morangueiro. Scientia Agraria, Curitiba, v. 12, n. 2, p. 069-074, 201 I.

OLIVEIRA, I. P. de; BELARMINO, L. C.; BELARMINO, A. J. Viabilidade da produção de morango no sistema semi-hidropônico recirculante. Custos e Agronegócio, v.13, n. I, p. 3015-332, 2017.

SOUZA, D. C. de et al. Variabilidade genética entre cultivares comerciais e híbridos experimentais de morangueiro com ênfase em análise de múltiplos fatores. Magistra, v. 30, p. 48-59, 2019.

TAGHAVI, T. SIDDIQUI, R.; RUTTO, L. K. The effect of preharvest factors on fruit and nutritional quality in strawberry. In: Strawberry-Pre-and post-harvest management techniques for higher fruit quality. IntechOpen, pp. I-22, 2019.

ZEIST, A. R.; RESENDE, J. T. V. de. Strawberry breeding in Brazil: current momentum and perspectives. Horticultura Brasileira, Vitoria da Conquista, v. 37, n. I, p. 7-16, 2019.

WURZ, D. A. et al. Desempenho agronômico de novos genótipos de morangueiro com potencial de cultivo no Planalto Norte Catarinense. In $10^{\circ}$ Seminário Brasileiro sobre Pequenas Frutas. Anais...Vacaria, p. I-5, 2019. 